\title{
Práticas musicais em Formiga/MG: um olhar para o século XIX
}

\author{
Vinícius Eufrásio \\ Doutorando em Música pelo Programa de Pós-Graduação em Música da \\ UFMG - Universidade Federal de Minas Gerais, tendo concluído o Mestrado \\ (2017) . Possui Especialização em Música Brasileira e Educação Musical (2013) \\ pela UNINCOR - Universidade Vale do Rio Verde; e Especialização em \\ Educação Musical com Ênfase em Música Popular (2015) pela UNIS - Centro \\ Universitário do Sul de Minas Gerais. Concluiu Licenciatura em Música com \\ Habilitação em Canto (2012) também pela UNINCOR. \\ vni_mus@hotmail.com
}


EUFRÁSIO, V.. Práticas musicais em Formiga/MG: um olhar para o século XIX. R. Cientifica UBM - Barra Mansa (RJ), ano XXIX, v. 21, n. 41, 2. Sem. 2019. p. 104-122.

ISSN 1516-4071

\section{Resumo}

Este trabalho aborda as práticas musicais do passado em Formiga, centro-oeste do estado de Minas Gerais, buscando, por meio de fontes documentais localizadas em acervos da cidade, construir uma narrativa capaz de identificar a práticas que ocorriam em seus espaços no século XIX. São apresentadas e discutidas fontes que rementem a distintos contextos e nos permitem reconhecer a atuação de determinadas personalidades em meio à atividade musical formiguense.

Palavras-chave: Musicologia. Música mineira. Música no século XIX. Música formiguense.

\section{Abstract}

This work addresses the musical practices of the past in Formiga, central-west of the state of Minas Gerais, seeking, through documentary sources located in the collections of the city, to build a narrative capable of identifying the practices that occurred in its spaces in the nineteenth century. Sources are presented and discussed that rehearse to different context and allow us to recognize the performance of certain personalities in the midst of the musical activity.

Keywords: Musicology. Minas Gerais music. Music in the nineteenth century. Music and culture. 


\section{Introdução}

Os acervos localizados na cidade de Formiga, região centro-oeste de Minas Gerais, têm sido explorados como detentores de potenciais fontes, capazes de revelar a existência de práticas musicais do passado, não só da cidade, mas também de uma grande parte da região. Nos fundos documentais existentes na cidade há elementos que podem auxiliar na compreensão do arcabouço político, social e cultural que fomentou e acolheu a atividade e produção musical ao longo de sua história, sendo um solo fértil para investigações que busquem analisar o papel e função da música produzida e praticada ao longo das formações comunitárias (EUFRÁSIO, 2018), pois, Formiga era um centro em torno do qual gravitam seus vizinhos (CORRÊA, 1993, p. 15).

A região do centro-oeste de minas, até o século XVIII, teria sido local de morada de diversas comunidades indígenas, mas com o descobrimento e popularização das jazidas na região de Goiás e a necessidade de caminhos até estas, que permitissem ações de combate ao contrabando, foi povoada e explorada em consonância com os interesses do governo, afinal, "o ouro constituía preocupação do governo" (CORRÊA, 1993, p. 20). É possível identificarmos evidências documentais que narram uma relação imensamente conflituosa entre os ocupantes dessa região e as comunidades quilombolas até finais do século XIX (PARREIRA, 2003).

Após cerca de um ano, com o avanço de minhas pesquisas na região, sobretudo acerca das escritas de memorialistas, viajantes e autores que abordaram a história da formação do município de Formiga, percebi que estes autores não abordavam as práticas musicais em seus relatos e que, quando se referiam aos anos iniciais de povoação desta localidade (séculos XVIII e XIX), sequer consideravam sua existência, mesmo diante de evidências que sugerem sua presença na região como espaços festivos, tabernas, bordeis, comunidades de negros e aldeamentos indígenas. 


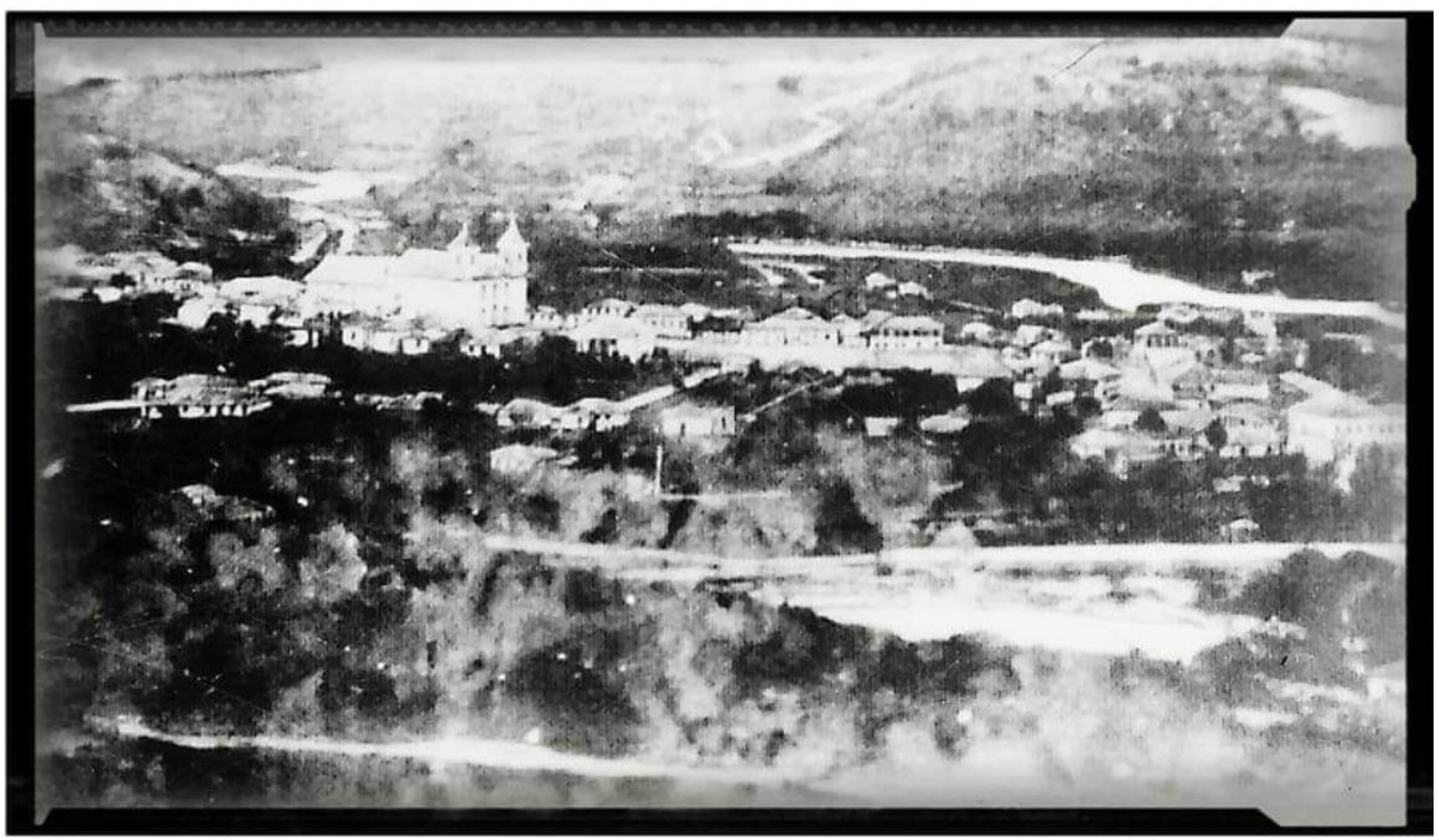

Figura 1: Fotografia mais antiga da cidade de Formiga, tirada em 1873, dia da inauguração do altar-mor da Igreja Matriz São Vicente Férrer

Já no século XVIII, havia um cotidiano religioso na cidade e foi determinante para o seu desenvolvimento cultural que teve início e prosperou a partir dos arredores da Igreja São Vicente Férrer, localizada na região central do município, onde foram erguidas as primeiras construções comerciais, residenciais e culturais (COELHO, 2016; EUFRÁSIO, 2018; SOBRINHO, 2007).

Nesse sentido, alço questões em torno da existência de práticas musicais na região de Formiga ao longo dos séculos XVIII e XIX, embora a primeira instituição de cunho musical, segundo a documentação até então levantada, seja a Corporação Musical São Vicente Férrer, fundada em 6 de junho de 1908, no aniversário de 50 anos de emancipação política do município (SANTOS, 2003).

Em uma localidade, incialmente povoada por comunidades indígenas, tomadas por brancos que deram lugar às suas fazendas e novas comunidades movidas pela mão de obra escrava que, em atos de resistência praticavam sua fé, seja aquilombando-se ou celebrando em seus terreiros e templos, não haveria de haver práticas com música? 
Escravos e libertos encontravam-se para orar, festejar seus deuses e lançar seus corpos na dança intensa dos batuques e candomblés; aí eles cantavam e falavam sobre suas tradições e seus ressentimentos, aí também conspiravam ou se levantavam (REIS; SILVA, 1989, p. 39).

Podemos considerar sua invisibilidade em dois sentidos: 1) A ausência de documentos, ou ainda a não realização de um levantamento, que nos possibilite averiguar a presença de grupos instrumentais e/ou vocais, pessoas, instituições que praticassem música a ponto que pudesse ser considerada como tal; 2) A ocorrência de eventos sonoros praticados por pessoas e/ou grupos que outrora, devido ao pensamento vigente, não eram considerados como produtores de arte, música, ou qualquer prática social, devido ao nível de exclusão extrema ao que estavam impostos.

\section{Fundamentação Teórica}

\section{Uma pergunta pela música...}

No ano de 1809, pelas mãos de sua irmandade, era concluída em Formiga a contrução da Capela de Nossa Senhora do Rosário (ver Figura 02), adquirido um sino em 1822 e ampliada em 1846, segundo os registros de seu fluxo financeiro (O DIÁRIO, 1962). Ficava localizada atrás da Igreja Matriz São Vicente Férrer (ver Figura 03) e era templo para os festejos de sua comunidade, como, por exemplo, o Reinado. Segundo relatos locais, sem uma expressiva intervenção comunitária, a contrução foi misteriosamente demolida entre os anos de 1965 e 1967.

Tendo em vista a Igreja do Rosário como espaço para prática da fé por pessoas da irmandade de negros, bem como as tradições festivas ligadas à devoção ao rosário e seu viés musical (COSTA, 2006; LUCAS, 2014) é difícil imaginarmos a ausência de práticas sonoras de cunho religioso, como os batuques e as rezas cantadas do povo negro em devoção aos seus santos e ancestrais. Sobre as Festas do Rosário em Formiga, o jornalista Claudinê Sílvio dos Santos relata: 
EUFRÁSIO, V.. Práticas musicais em Formiga/MG: um olhar para o século XIX. R. Científica UBM - Barra Mansa (RJ), ano XXIX, v. 21, n. 41, 2. Sem. 2019. p. 104-122.

Ainda no século XVIII, nossa pequena freguesia já vivia uma grande festa religiosa [...] Incentivados pelo padre Francisco da Anunciação Teixeira Coelho, os 4.800 escravos que aqui residiam na grande paróquia de São Vicente, que se estendia desde o rio Grande até o São Francisco em Porto Real, praticavam a dança, que era uma maneira de amenizar o jugo imposto pela escravidão [...] fato que fortalecia muito a prática da devoção a Nossa Senhora do Rosário. Já concluída, a velha Igreja do Rosário, era então o palco dos brincantes (SANTOS, 2005 s. p.)

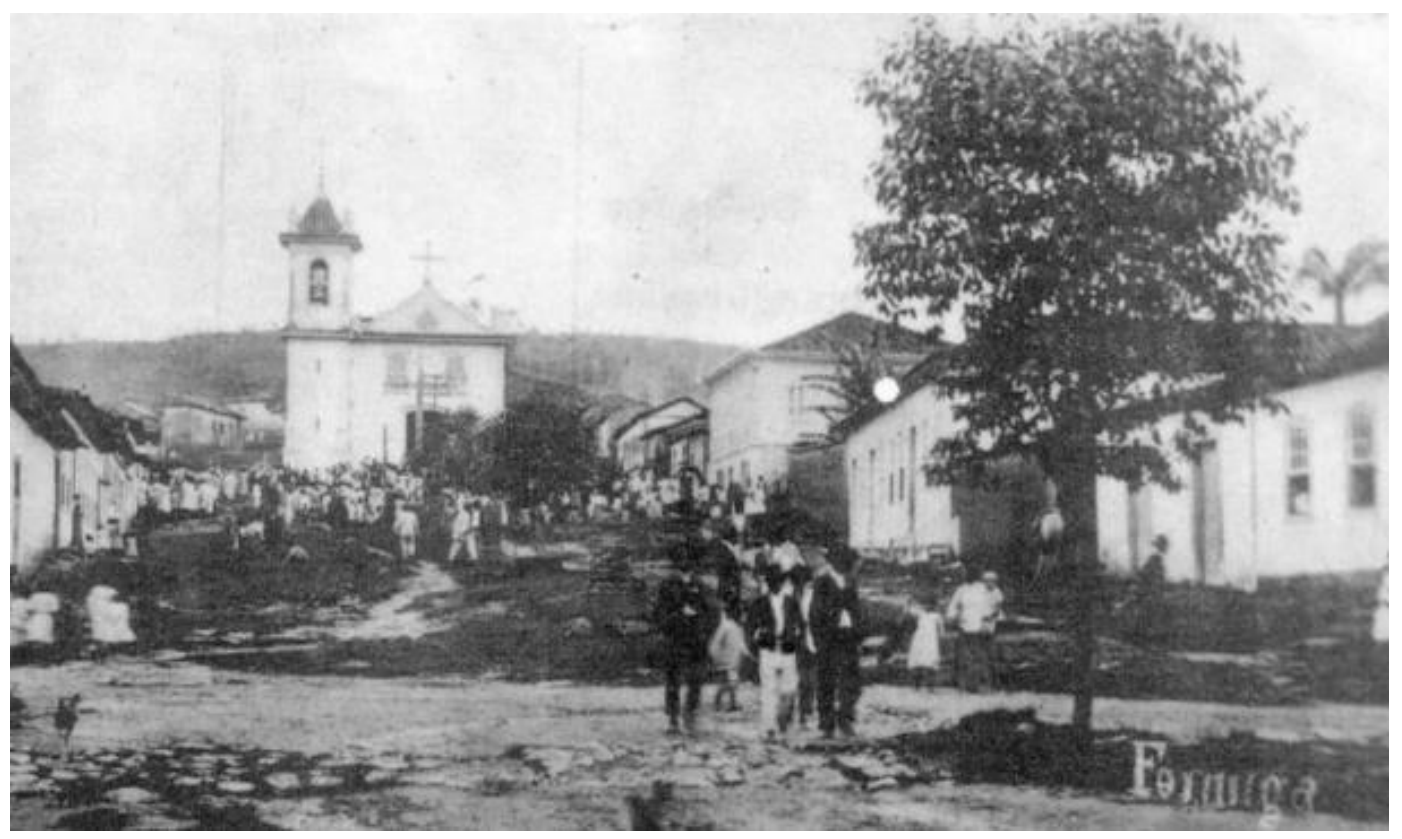

Figura 2: Antiga Igreja do Rosário em Formiga

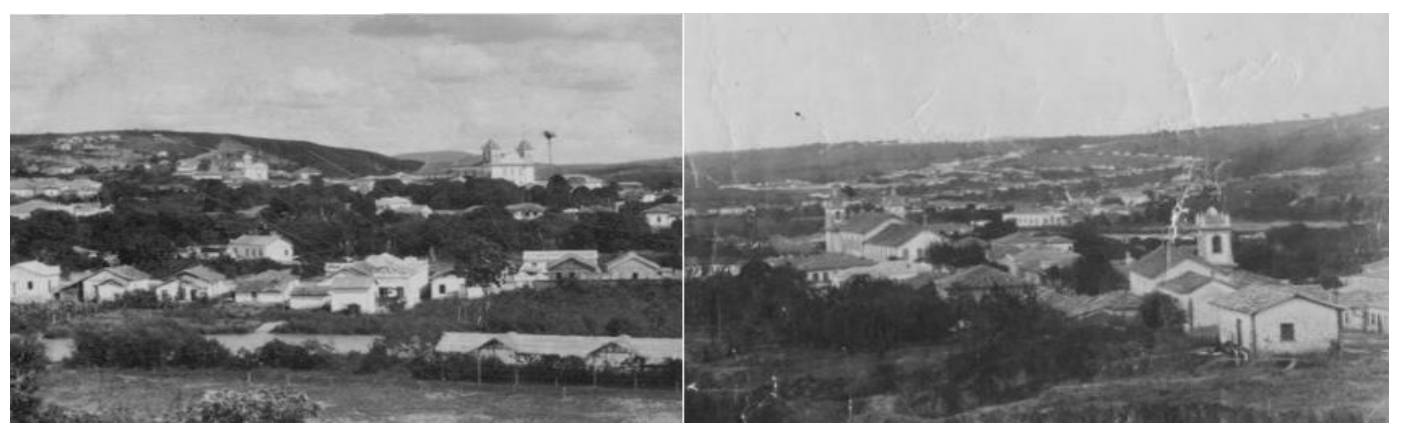

Figura 3: Vistas panorâmicas da Igreja do Rosário e Igreja São Vicente Férrer no final do século XIX 
A devoção aos santos é documentada pelo registro de assasinato do escravo Feliciano, ocorrido em 1862, um episódio flagrante que sugere sua fé a São Benedito, Santa Efigênia e Nossa Senhora do Rosário. Ele fora apreendido por tropeiros rumo à Goiás (rota comum daqueles que se arranchavam na região) os quais suspeitaram que o indivíduo era um escravo fugido, pois, conforme consta "já vinha surrado de trás" e carregava um pequeno balaio contendo imagens de santos, demonstrativos de sua fé e possivelmente aquilo que teria de mais caro: a crença na proteção dos santos (PARREIRA, 2003, p. 43-45).

Muitos quilombos e mocambos - núcleos de escravos que pressupõem as fugas individuais e coletivas e ao aglomerado destes indivíduos - se localizaram na região de Formiga, alguns perduraram por anos e outros por períodos curtos. Alguns concentravam muitos indivíduos, tendo como exemplo mais expressivo o grande Quilombo do Ambrósio. Os registros sobre sua localização são imprecisos e controversos em meio a história do Sertão de Campo Grande. Alguns autores o identificam como tendo início entre a localidade de Formiga e o Rio Grande, a noroeste dessa povoação, passando por onde atualmente encontram-se os municípios de Arcos, Bambuí e estendendo-se até a Serra da Marcela, na região do município de Campos Altos. "Não há, pois, dúvida de que existiu um Quilombo do Ambrósio na divisa de Formiga com Cristais, no Campo Grande" (CORRÊA, 1993, P. 26).

A pesquisadora Jacyra Antunes Parreira (2003) investigou, nos documentos presentes no arquivo do Fórum Magalhães Pinto, algumas situações de crimes resultantes da relação conflituosa entre os brancos povoadores da região e as comunidades quilombolas existentes em torno de Formiga, demonstrando uma trama de relações complexas na conjuntura social. Dentre os casos estudados pela autora é possível identificarmos evidências que demonstram práticas musicais. Em processos criminais e depoimentos transcritos na segunda metade do século XIX, a autora analisou as relações sociais entre dois grupos étnicos que coexistiam na localidade. Por outro lado, buscando por práticas relacionadas ao fazer musical, identificamos em sua pesquisa fortes evidências para o desenvolvimento deste estudo, bem como motivação e caminhos para buscarmos informações remotas sobre a vida e as práticas musicais em Formiga.

A existência desses espaços na região e seu cariz enquanto espaços de recriação cultural dos negros sugere a existência de práticas sonoras em território formiguense, 
porém, cabe-nos questionar se poderiam ser consideradas como atividades musicais em Formiga, uma vez que seus praticantes, embora presentes na vida cotidiana da localidade, não se encontravam inseridos na sociedade enquanto cidadãos e, consequentemente, tampouco ocupavam um lugar de reconhecimento social. Entretanto, o trânsito por espaços comuns na Formiga do século XIX, como na Taberna da Rita Liberata, ocasionava o convívio de indivíduos e grupos de distintas raças e posições sociais, interagindo em momentos onde podemos pressupor que haveria prática musical.

Como foi o caso de Manoel e seus companheiros, que se reuniram na taberna da Rita Liberata, três dias antes do crime [...] Lá estavam, Hortência de 40 anos mais ou menos, Domingos Gonçalves Cerqueira com sua caseira, Rita do Aquiles e um crioulo, Joaquim [...] Mais tarde, juntaram-se a eles três mulatos e um crioulo. Apresentados por Rita do Aquiles como carreiros. Justificou que estavam arranchados no Morro das Balas porque "iam comprar sal longe dali” e aproveitavam a folga para suciar, tocar viola, dançar e beber [...] Altas horas, Rita já bastante "esquentada de caxaça" confidencia à dona da casa que "os pretos eram escravos fugidos e aquilombados" por isso não deveria dançar com eles e nem dar confiança demais. Então, Rita Liberata, a dona do rancho, depois do aviso reclamou de "incomodo de saúde" e foi se deitar, recomendando a casa de seu genro, Zé Beirigo que prometeu "zelar de tudo" (PARREIRA, 2003, p. 56-57).

Podemos considerar que as tabernas são um elo entre o lícito e o ilícito, passíveis de incorporar caracterizações que as enquadram como espaços para elaboração cultural e política, pois, como exemplificado por Jacyra Parreira, era na taberna da Rita Liberata que escravos, ex-escravos, quilombolas e escravos fugidos se reuniam em ocasiões de negociação e para fins diversos.

O caso de crime cometido por Manoel da Cruz e seu bando, ocorrido em agosto de 1867 e registado na caixa 1870 do arquivo do Fórum Magalhães Pinto serve a essa investigação como evidência da presença de práticas musicais na região na segunda 
metade do século XIX, pois, em uma das "súcias"1 ocorridas da Taberna da Rita Liberata, munido de uma viola, ficou "pagodeando com elles" (PARREIRA, 2003, p. 57).

Perguntada sobre o que acontecia nas reuniões, Rita do Aquiles descreveu-a: "A súcia constou de toques de violla, cantoria, dansa,de catêrêtê, café, biscoutos, e caxaça, destinguindo-se nos toques, cantoria e dansa, o mulato Feliciano que tinha sinais na cara." Noutro dia repetiram a súcia, dessa vez em outra casa, de Joaquim Custódio, o grupo era o mesmo da noite anterior. As reuniões onde se encontravam a escravaria e libertos, seja para dançar ou comer sugeriam conspiração. Planos eram traçados, negócios feitos. A intimidade e exclusividade daquele momento por si só sugeriam conluio (PARREIRA, 2003, p. 57-58).

Por meio de um jongo cantado que remanesce do tempo dos escravos que residiam na Fazenda Tamboril e cujos versos eram entoados como oração - recolhidos através de moradores da região que hoje pertence ao município de Pains, mas que, no século XIX, compunha o extenso território de Formiga - podemos, mediante a interpretação do sentido de suas palavras perante do contexto no qual estavam inseridos os negros, perceber seus desejos e reconstruir na imaginação uma síntese do sofrimento ao qual eram submetidos e a pressão da vida sob cativeiro e maus tratos.

Nos versos e cantos dos escravos, entoados como oração, são palpáveis seus desejos. Em momentos de extrema tensão, como no caso das fugas, repetiam: " Tomara que chove muito pro lado de onde vim pra apagá meus rastro ,pra ninguém saber de mim" (PARREIRA, 2003, p. 45)

\footnotetext{
${ }^{1}$ Grupo de indivíduos de péssima reputação ou de má índole; corja. Festejo de ambiente familiar; festança ou farra. A convivência em família; sociedade. Disponível em: https://www.dicio.com.br/sucial. Acesso em: 23/06/2019.
} 
A situação de fugas de escravo era crítica, em Formiga, na década de 1860, demonstrando o aumento de aglomerações quilombolas na região. Em 1868 a tensão chegava a níveis desesperadores, levando diversos fazendeiros a buscarem apoio nas autoridades locais que, por sua vez, solicitaram reforços às instâncias superiores para a captura ou extermínio dos escravos fugidos que provocavam transtornos na ordem da cidade e se aglutinavam no Quilombo da Ponte Alta.

As informações advindas desses processos, que deflagram as relações cotidianas existentes entre livres, cativos e quilombolas, demonstrando proximidade e interação entre esses estratos sociais por meio de situações que permeavam os conflitos que ascendiam em meio ao regime escravocrata que assolava a parcela negra da população. Neste cenário complexo, cujos relatos presentes na documentação dão testemunho, prática com o sonoro: danças, pagodeio e devoções aos santos, surgem como um plano de fundo em meio ao contexto da vida formiguense no século XIX, imprimindo funções e simbolismos.

\section{Uma banda de música no século XIX?}

Dentre as instituições musicais aparentemente mais remotas, a primeira banda cujos registros iconográficos, hemerográficos e que a documentação obtivemos acesso foi a Corporação Musical São Vicente Férrer, fundada por Pedro Músico e colegas que trabalhavam na construção da Estrada de Ferro Oeste de Oeste no ano de 1908. A história da Corporação Musical São Vicente Férrer (ver Figuras 04 e 05) teve início com Pedro Severiano de Deus (1880-1920)², popularmente conhecido como Pedro Músico. Foi pedreiro e operário por profissão, contudo, atuou como primeiro presidente e maestro da corporação que fundou a partir do apoio do então prefeito José Bernardes de Faria, do juiz de direito Dr. José Maria de Moura Leite e dos religiosos Padre João da Mata da Silva Rodarte e Monsenhor João Ivo Rodarte ${ }^{3}$, seu primeiro professor de música e com o qual aprendeu a tocar baixo.

\footnotetext{
${ }^{2}$ Há informações que mencionam Pedro Severiano de Deus como um dos fundadores do Centro Operário Formiguense em 1925.

${ }^{3}$ Aparentemente, também foi um dos grandes incentivadores da devoção à Nossa Senhora do Rosário.
} 


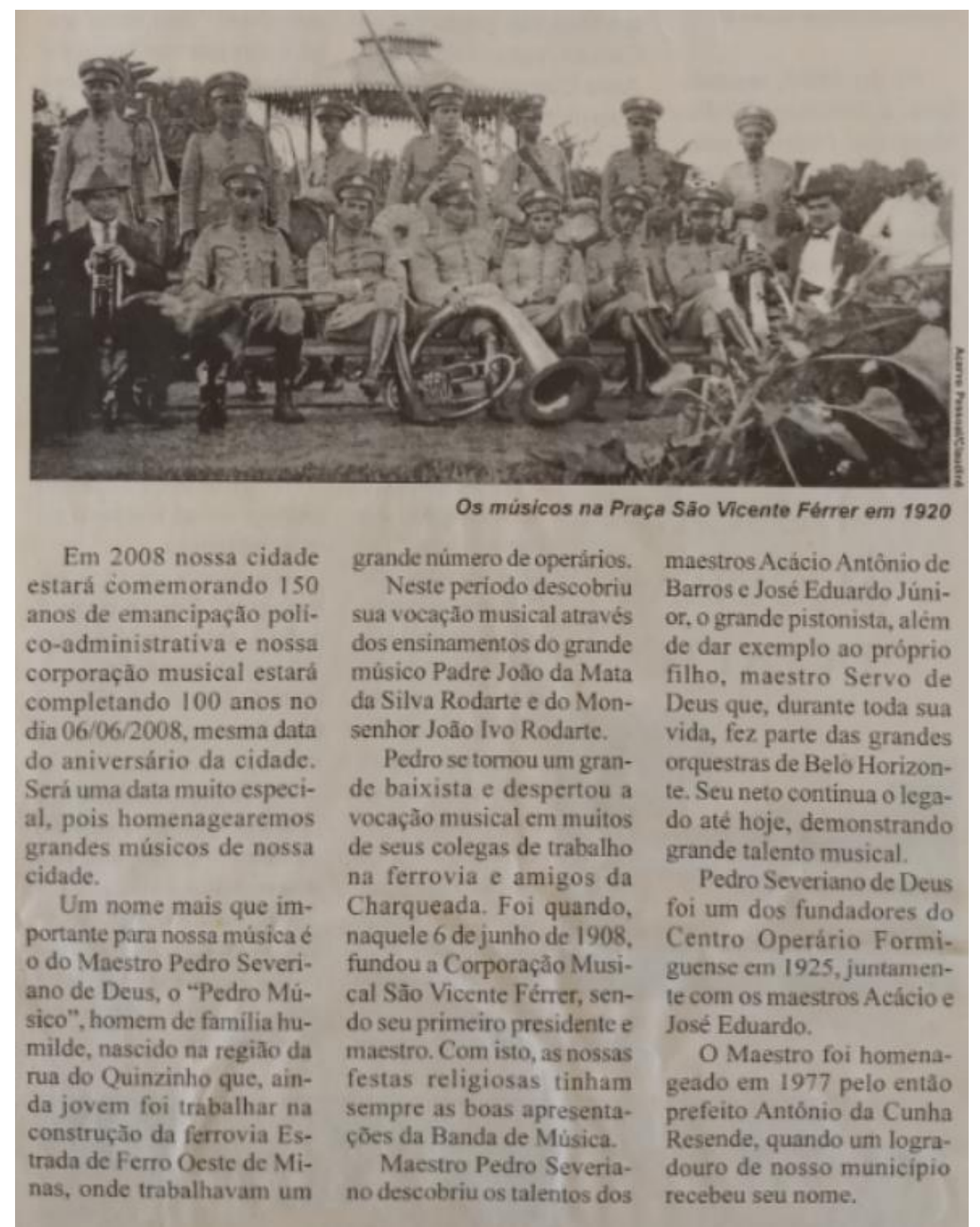

Figura 4: Recorte de jornal do ano de 2007 encontrado em meio aos materiais do acervo do jornalista Claudinê Sílvio dos Santos

A banda foi formada por colegas do Maestro Pedro Severiano de Deus e operários da Estrada de Ferro Oeste de Minas, dentre estes, por meio de um levantamento hemerográfico, conseguimos identificar ainda quatro integrantes: Sr. Boffa, italiano que tocava trompa; Acácio Antônio de Barros; José Eduardo Júnior, que 
veio a ser maestro da banda em décadas posteriores ${ }^{4}$; e Saulo de Deus, filho de Pedro Música, pistonista com carreira de grande sucesso em orquestras na capital (SANTOS, 2003a, 2007). A primeira apresentação da Corporação Musical São Vicente Férrer ocorreu no dia 6 de junho de 1908, aniversário de cinquenta anos de emancipação política do município (SANTOS, 2003a, 2007). Como complemento, consta na documentação localizada no acervo da Secretaria Municipal de Cultura, a Corporação Musical São Vicente Férrer teve seu reconhecimento público por meio da Lei Municipal de no 695, publicada no dia 17 de outubro de 1968.

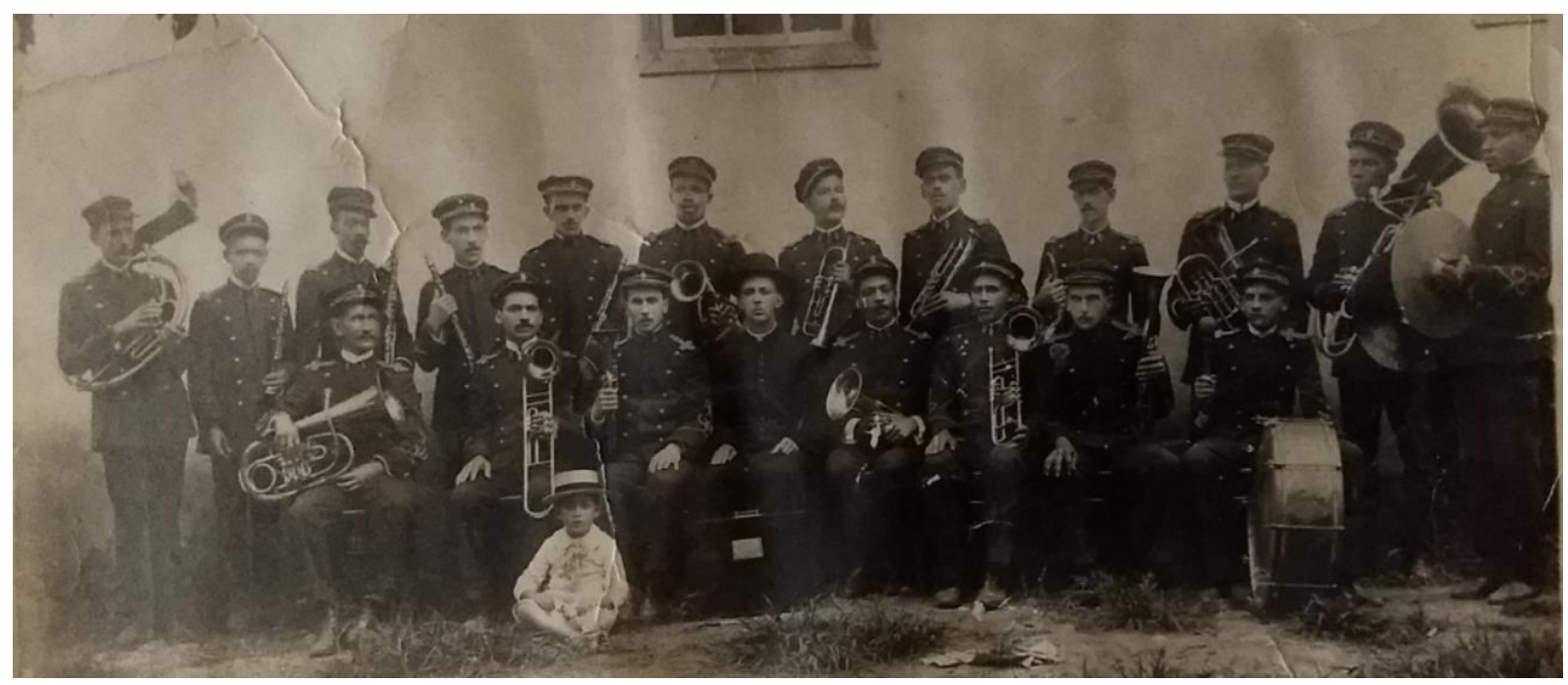

Figura 5: Corporação Musical São Vicente Férrer em 1920

Por outro lado, existem algumas evidências que nos permitem cogitar a existência de outros grupos instrumentais que praticassem música em Formiga já no século XIX. A primeira delas é a menção à Orchestra Lyra Formiguense em matéria do jornal Cidade de Formiga, publicado em 24 de abril de 1924, homenageando Juca Pedro (1857-1924) em ocasião de sua morte. No jornal é mencionada uma breve biografia de Juca na qual o mesmo é mencionado como presidente da Orchestra Lyra e, em 1923, diretor da Banda de Música Santa Cecília.

\footnotetext{
${ }^{4}$ Há fontes que atribuem as funções de maestro também à Acácio Antônio de Barros. Com o falecimento de Pedro Músico em 1920 podemos imaginar que José Eduardo e Acácio assumiram a regência do grupo, porém há documentos musicográficos no acervo da banda com a assinatura de José Geraldo da Silva que datam esta época.
} 
Até o presente momento não foram encontradas informações que permitissem identificar maiores detalhes sobre a formação e a atuação da Banda de Música Santa Cecília. Porém há menções sobre a Orchestra Lyra ${ }^{5}$ Formiguense informando sobre sua formação e atividade a partir de 1885 por meio da atuação de vários músicos e tendo o total apoio do Monsenhor João Ivo. Essa mesma fonte informa que a Lyra Formiguense, devido ao grande número de músicos que possuía, deu origem à dois outros grupos: 1) Corporação Musical São Vicente Férrer e; 2) Banda do Santo Antônio, comanda por Juca Bicho e Sr. Boffa (SANTOS, 2003), porém sobre este grupo não obtivemos qualquer outra informação ou identificamos qualquer documentação específica. Um dos locais que servia de palco para estes grupos se apresentarem era o Theatro Alecrim, inaugurado em 1887 e passando a se chamar Cine Theatro Municipal de 1917 até 1951, quando foi consumido por um incêndio e com o fogo se perdeu parte da história da arte formiguense ${ }^{6}$.

\footnotetext{
${ }^{5}$ Seu nome aparece grafado como "Lyra" e "Lira".

${ }^{6}$ No local onde encontrava-se a construção, atualmente funciona como estacionamento da Prefeitura Municipal de Formiga.
} 


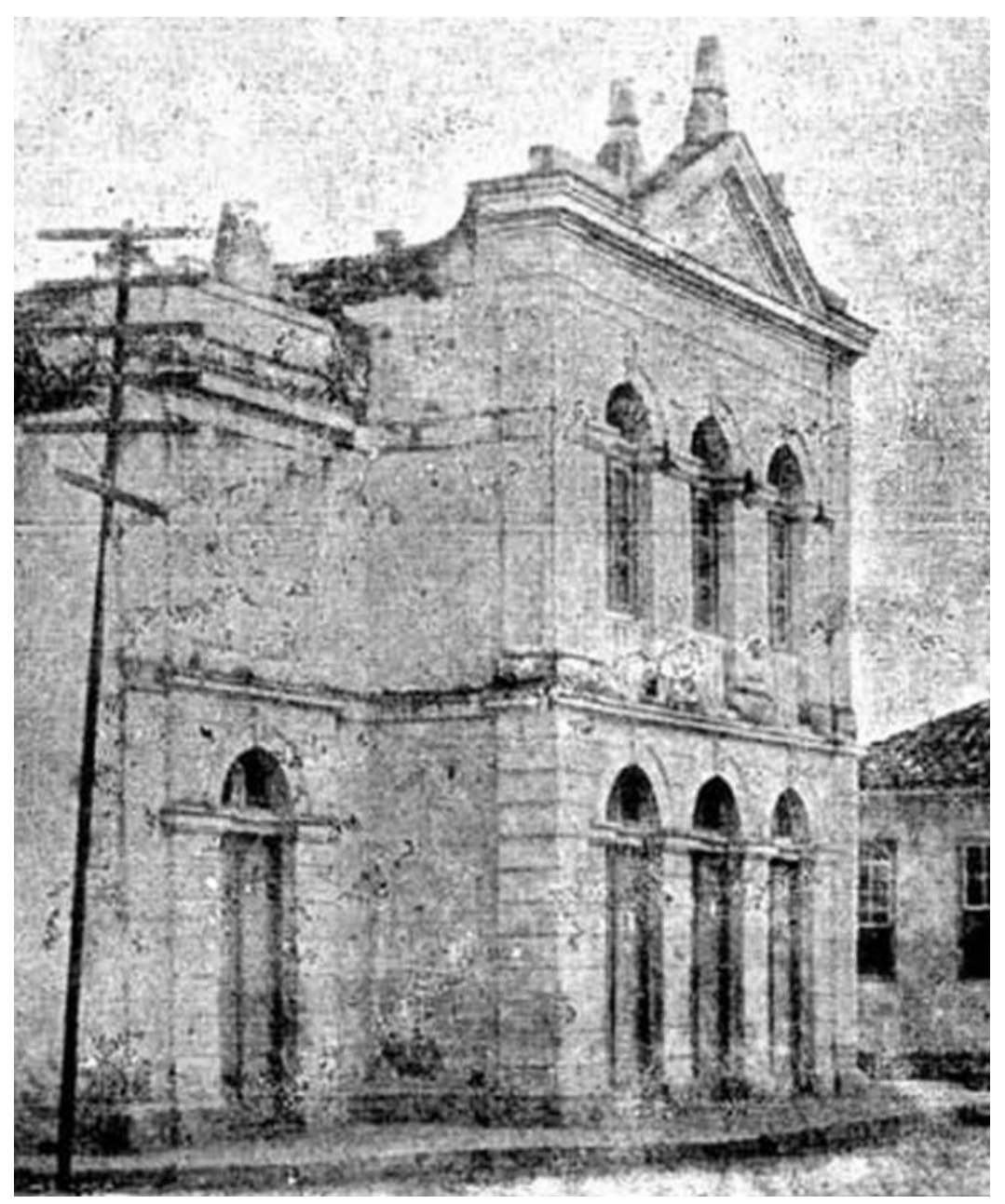

Figura 6: Cine Theatro Municipal da cidade de Formiga 


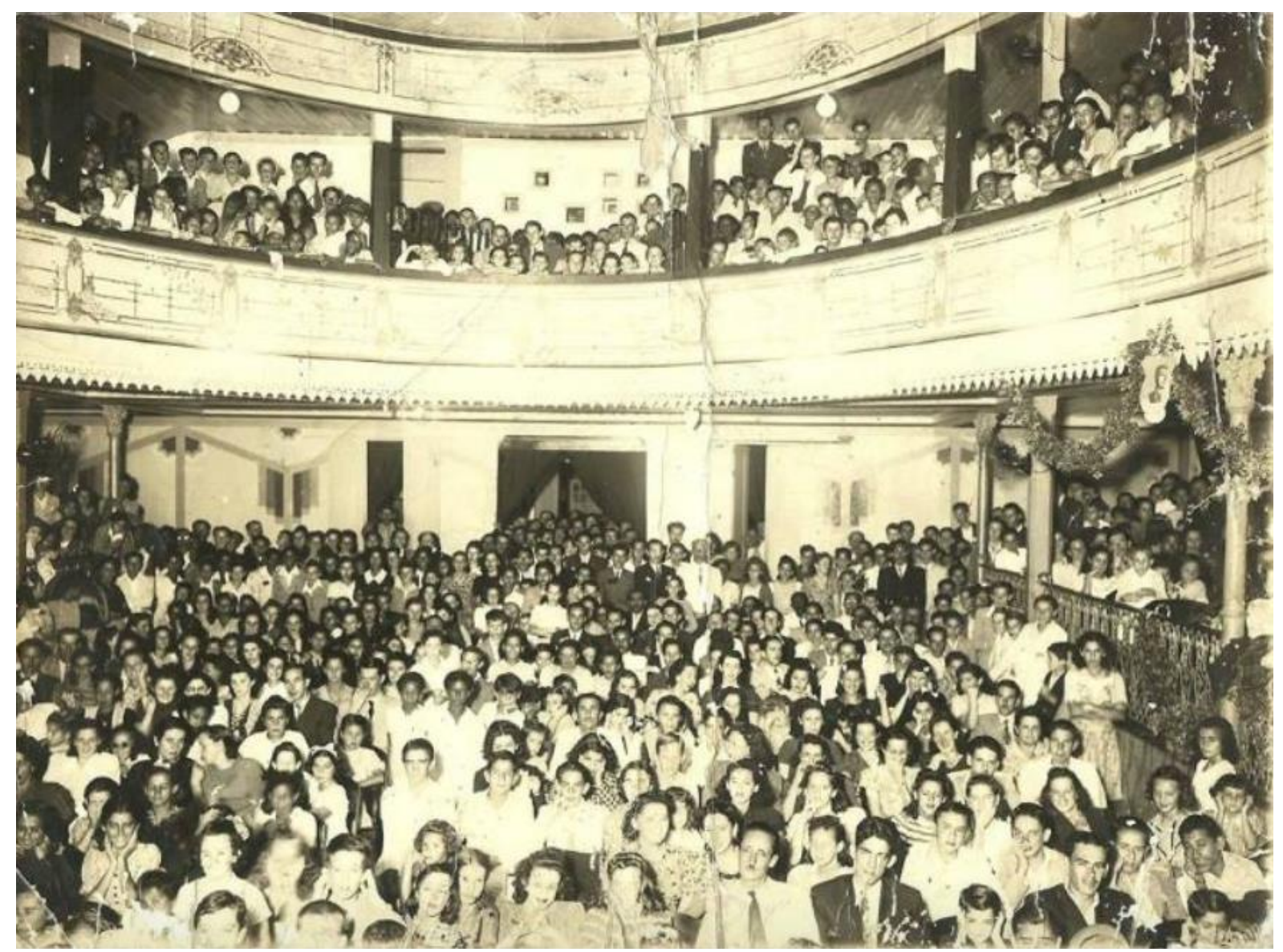

Figura 7: Interior do Cine Theatro Municipal em 14 de dezembro de 1942

No jornal Correio da Formiga, publicado em 31 de maio de 1903, é noticiada a programação da festa ao Martyr São Sebastião incluindo espaços com música, leilão de prendas, fogos de artifício, um grande balão de ar, missa cantada e sermão. $\mathrm{Na}$ programação que compreende os dias 05, 13 e 14 de junho de 1903 é mencionado que "todos os actos serão abrilhantados com excelentes peças musicaes habilmente executadas pela festejada banda Santa Cecília” (FRANÇA, 1903, p. 4). Tendo em vista o notório prestígio atribuído a essa banda, podemos inferir que sua atividade advém dos anos anteriores e que, possivelmente já estava em atividade no final do século XIX .

Outra documentação trata-se de uma partitura datada em 1898, uma missa coral, encontrada em meio ao acervo de partituras da Corporação Musical São Vicente Férrer

\footnotetext{
7 Uma vez, pesquisando em jornais foi possível identificar uma notificação acerca de uma festa a São Sebastião que ocorrera no ano de 1898 e contou com a presença de uma banda de música, porém, na ocasião da redação do presente texto, não foi possível localizar a fonte para sua inclusão neste estudo.
} 
que, segundo memorialistas, atuava nos eventos civis e também sacros, umas vez que nem sempre estes dois contextos são divididos por uma demarcação linear e nítida devido à uma trama de relações sociais e até mesmo em respeito à vínculos pessoais, como poderia ter sido o caso entra a Banda São Vicente e a Paróquia, uma vez que Pedro de Deus aprendeu música com Monsenhor João Ivo.

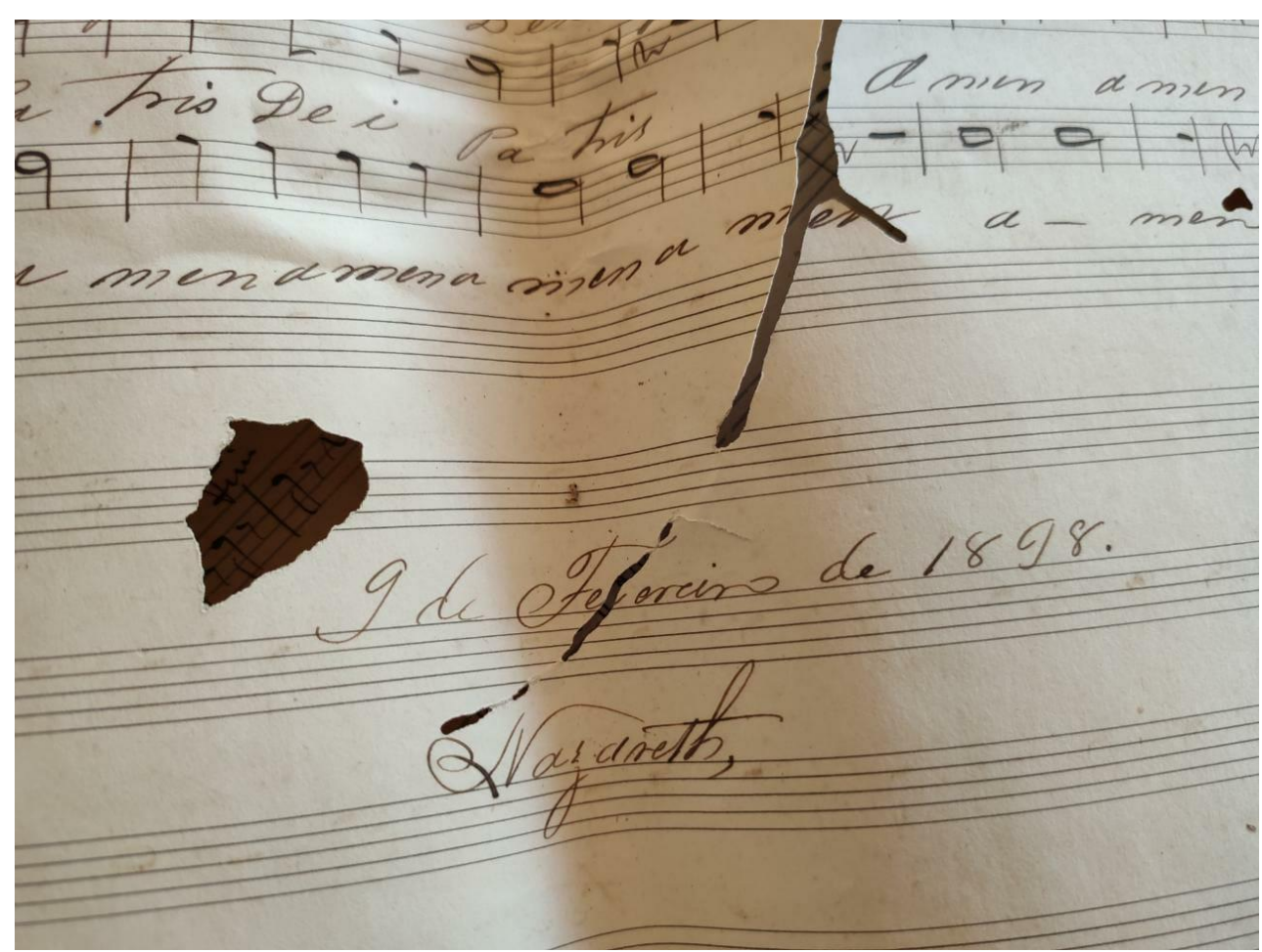

Figura 8: Excerto musicográfico da "Missa Cathedral” encontrado no acervo da Corporação Musical São Vicente Férrer

Ao que tudo indica, esse excerto pertence a duas partes avulsas, tenor e soprano, de uma missa e está junto aos documentos musicográficos da Corporação Musical São Vicente Férrer, porém, por se tratar de uma peça coral sem qualquer acompanhamento instrumental ainda identificado no conjunto do acervo não foi possível averiguar que compunha o repertório sacro executado pela banda.

Outra importante documentação pode ser acessada a partir do trabalho de José Sobrinho e os diversos documentos cujas transcrições estão presentes em sua volumosa obra que trata da historiografia, história e genealogia formiguense. Nos dados apresentados pelo autor, coletados em diversos órgãos da cidade e fora dela, o autor, traz informações sobre o ofício de diversos moradores da cidade ao longo do século XIX, 
tendo, dentre estes, um músico por profissão, identificado como Antônio da Silveira, de 71 anos, segundo o censo de 1831 (SOBRINHO, 2007, p. 599). Nas atas de eleições da Câmara Municipal de Formiga, no ano de 1852, dentre os eleitores, são identificados, no campo referente à profissão, quatro violeiros: Antônio Luciano de Oliveir, de 69 anos; Antõnio Luciano de Oliveira Júnior, 37 anos; Clemente Luciano de Oliveira, 41 anos; Cândido Pio de Oliveira, 31 anos; possivelmente membros de uma mesma família que habitava, por época, o $15^{\circ}$ quarteirão (SOBRINHO, 2007, p. 317).

\section{Considerações Finais}

Após cerca de um ano, com o avanço das pesquisas na região, sobretudo acerca das escritas de memorialistas, viajantes e autores que abordaram a história da formação do município de Formiga, foi possível perceber que estes autores frequentemente não abordavam as práticas musicais em seus relatos ou que pouco se preservou da documentação que se referiam aos anos iniciais de povoação desta localidade (séculos XVIII e XIX).

Podemos identificar também a existência de pouca documentação em periódicos locais e iconografia no que diz respeito às práticas musicais pertencentes à cultura negra, como o Rosário de Nossa Senhora do Rosário aparentar ser um evento silenciado pelo olhar jornalístico ou pelos que optaram por preservar algumas fontes em detrimento de outras, pois, mesmo diante das evidências que sugerem sua forte presença na região, parecem ficar fora da atenção se comparado às bandas de música. De forma geral, encontramos, até então, pouca evidência em relação aos festejos populares e a atividade musical em tabernas, bordéis, comunidades de negros e aldeamentos indígenas, este que, segundo relatos, descrições de viajantes e memorialistas locais, eram numerosos.

Ao voltarmos nosso olhar para a narrativa existente na história produzida pela musicologia considera Kevin Korsyn (1999) como tradicional, veremos que os discursos sobrevêm para tornar contínuo o que é descontínuo, buscando cobrir lacunas no tempo, na ação e na documentação, promovendo a continuidade de narrativas através do uso do que o autor denomina como "contextos privilegiados" e que constituem várias formas de composições para criar narrativas históricas de conjunturas específicas. São tidas como “privilegiadas” porque, na crítica de Korsyn, na construção de narrativas são utilizados 
um número limitado de contextos, preferindo certos tipos de locais, pessoas e práticas com o sonoro em detrimento de outras. Isso nos faz perceber que uma série de contextos se tornam estereotipados e previsíveis, limitando as perguntas que fazemos sobre música. Talvez em Formiga, e em várias outras localidades do país, dado o histórico da colonização, contexto privilegiados tenham prevalecido na história em detrimento de outros que, por fatores sociais, culturais e de poder, tenham sido fadados ao silêncio.

Até o presente momento, tem sido possível ver de forma panorâmica que o contexto formiguense e sua formação enquanto município foi um terreno fértil para manifestações culturais e artísticas, entretanto, nossos esforços ainda são incipientes para processar a quantidade de materiais encontrados em fundos documentais (EUFRÁSIO, 2018; EUFRÁSIO; ROCHA, 2017, 2019), textos de antigos moradores, e "causos” que passam de geração para geração ao longo dos anos através da narrativa de pessoas que, apaixonadamente, contam histórias do passado com propriedade tamanha como se fossem parte de sua própria vida... E talvez, realmente sejam...

\section{Referências}

COELHO, P. H. P. A formação do Arraial de São Vicente Férrer da Formiga: o povoamento do Oeste de Minas Gérais (séculos XVIII-XIX). In: AZEVEDO, F. L. M. DE et al. (Eds.). . História e Memória do Centro Oeste Mineiro: perspectivas. $1^{\text {a }}$ ed. Belo Horizonte: O Lutador, 2016. p. 36-51.

COSTA, P. T. M. As Raízes da Congada: A renovação do presente pelos filhos do rosário. [s.1.] Universidade de Brasília, 2006.

EUFRÁSIO, V. Música na Princesa D ’ Oeste de Minas Gerais : possibilidades de pesquisas musicológicas em fundos arquivísticos localizados em Formiga. XXVIII Congresso da ANPPOM. Anais...Manaus/AM: Associação Nacional de Pesquisa e Pós-Graduação em Música, 2018

EUFRÁSIO, V.; ROCHA, E. O Museu Histórico Municipal Francisco Fonseca: desafios e impactos do seu arquivo musical na construção da história da música 
formiguense. I Encontro de Musicologia Histórica do Campo das Vertentes. Anais...Sâo João Del Rei: Universidade Federal de São João del Rei, 2017 EUFRÁSIO, V.; ROCHA, E. Fontes para o estudo da música formiguense: salvaguarda, identidades e instituições a partir dos documentos acomodados na secretaria municipal de cultura. I Encontro de Musicologia Histórica do Campo das Vertentes. Anais...São João Del Rei: Universidade Federal de São João del Rei, 2019 FRANÇA, J. Festa do Martyr S. Sebastião no dia 14 de junho próximo. Correio da Formiga, p. 4, 31 maio 1903.

LUCAS, G. Os Sons do Rosário: O Congado Mineiro dos Arturos e Jatobá. 2a ed. Belo Horizonte: Editora UFMG, 2014.

O DIÁRIO. Formiga há 150 anos. O Diário, p. 7, 10 jun. 1962.

PARREIRA, J. A. "Meu passaporte é esse pau e essa faca": Quilombolas e pretos em movimento no município de Formiga (1843-1888). [s.1.] Universidade Severino Sombra, 2003.

REIS, J. J.; SILVA, E. Negociação e Conflito: a resistência negra no Brasil escravista. $1^{\text {a }}$ ed. São Paulo/SP: Companhia das Letras, 1989.

SANTOS, C. S. DOS. Banda de todas as bandas. Jornal Nova Imprensa, 2003.

SANTOS, C. S. DOS. Festa do Rosário. Nova Imprensa, ago. 2005.

SOBRINHO, J. F. DE P. A formação histórica das comunidades no Brasil: estudo da criação do Arraial São Vicente Férrer da Formiga. Sua história e sua gente. 1ª ed. Belo Horizonte: Editora Del Rey, 2007. 